\title{
Numerical Modeling of the I-V Characteristics of Carbon Nanotube Field Effect Transistors
}

\author{
Jose Mauricio Marulanda and Ashok Srivastava \\ Department of Electrical and Computer Engineering \\ Louisiana State University \\ Baton Rouge, LA 70803, USA
}

\section{Introduction}

Carbon nanotubes (CNTs) were first discovered in 1991 by Sumio Iijima (Iijima, 1991), and they have been a rapid and successful target of development by many researchers (Baughman et al., 2002). Especially with the end of Moore's law in sight (Wind et al., 2002), CNTs are being considered as possible candidates substituting silicon in the fabrication and design of analog and digital integrated circuits (ICs) (Guo et al., 2002; Wong, 2002).

Carbon nanotubes are basically two dimensional graphene sheets rolled into a one dimensional tubular structure (Martel et al., 1998). Their properties are determined by the chiral vector represented by the indices (n,m) (Tanaka et al., 1999; Wallace, 1947; Wildoer et al., 1998). Depending on the number of layers rolled, carbon nanotubes can be either single walled (one layer), or multi walled (two or more layers) (Dresselhaus et al., 2001). Single walled carbon nanotubes (SWNTs) are used in the fabrication of carbon nanotube field effect transistors (CNT-FETs), the first CNT-FETs were implemented in 1998 (Martel et al., 1998; Tans et al., 1998). The structure of a CNT-FET is similar to the structure of a typical MOSFET where the CNT forms the channel between two electrodes that work as the source and the drain of the transistor. The structure is build on top of an insulating layer and a substrate wafer that works as the back gate, (Nihey et al., 2003) (Wind et al., 2002). The basic structure of a CNT-FET based on a SWNT is shown in Fig. 1. Among the CNT-FETs reported (Martel et al., 1998; Wind et al., 2002), a $40 \mathrm{~nm}$ gate length transistor (Lin et al., 2005), a multistage complementary logic (Javey et al., 2002), oscillators (Chen et al., 2006), and an $80 \mathrm{GHz}$ operating field effect transistor (Nougaret et al., 2009) have been achieved.

In addition, carbon nanotubes are one-dimensional conductors (1D), which confines the electrons to only back-scattering effects. This property provides a large electron mean free path in metallic carbon nanotubes of usually a few micrometers (White \& Todorov, 1998). Carbon nanotubes also exhibit large current capabilities of $\sim 10^{-9} \mathrm{~A} / \mathrm{cm}^{2}$, (Wei et al., 2001; Yao et al., 2000) and it has also been reported that doping can be avoided in the CNT fabrication process, yet still achieving complementary CNT-FETs (Zhang et al., 2007). With carbon nanotubes interconnects being also a major target of research (Koo et al., 2007; Xu et al., 2008) and a completely carbon nanotube based integrated circuit (IC) already reported 
(Liang et al., 2009), fabrication of fully integrated carbon nanotubes in custom designed ICs and systems on a chip is no longer a future circuit design promise but an attainable grasp.

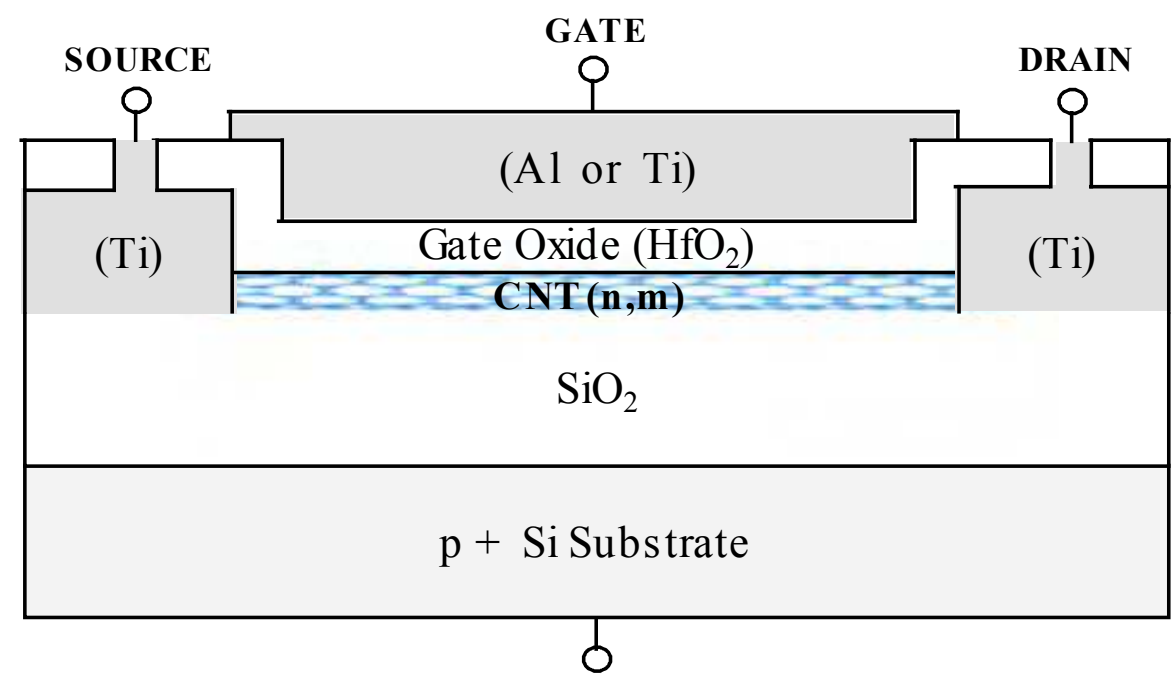

BACK GATE

Fig. 1. Cross sectional view of a CNT-FET. Note: $\mathrm{HfO}_{2}$ (Halfnium dioxide) is a high $k$ dielectric ( 17-20) (Javey et al., 2004; Wang et al., 2003).

In this paper, we have used our modeling of the potential and charge balance of CNT-FETs (Marulanda, 2009; Marulanda et al., 2008; Srivastava et al., 2009) to develop a numerical model of the current-voltage relation for a CNT-FET of n-type behaviour. This model uses numerical approximation methods to solve this current and voltage equations and present the I-V characteristics of different CNT-FETs.

\section{Current Equation}

The current per band in a semiconductor (Datta, 1999; Xia et al., 2004) can be expressed as:

$$
I_{d s_{i}}=\frac{q}{\pi \mathrm{h}} \int_{E_{c_{i}}}^{E_{\text {max }}} T_{i}(E)\left[f_{s}(E)-f_{d}(E)\right] d E,
$$

where $E_{c i}$ and $T_{i}(E)$ are respectively the conduction band energy minimum and transmission coefficient for the $i_{\text {th }}$ band, $h$ is Planck's constant divided by $2 \pi$, and $f_{s}(E)$ and $f_{d}(E)$ are the Fermi distributions at the source and drain, respectively.

Although the total $I_{d s}$ will be the sum of all $I_{d s i}$ over all bands, the summation in Eq. (1) can be dropped, as only the first band is sufficient. The reason is because the remaining energy bands will have negligible contribution to the current due to the vanishing exponential behaviour of the Fermi distribution for high-energy conduction band values. 
By letting the limit of $E_{\max }$ go to infinity and the transmission coefficient be a constant equal to unity for the energy range of integration, Eq. (1) becomes (Marulanda et al., 2008):

$$
I_{d s}=\frac{q K T}{\pi \mathrm{h}}\left\lfloor\ln \left(1+e^{\frac{E_{F s}-E_{c}}{K T}}\right)-\ln \left(1+e^{\frac{E_{F d}-E_{c}}{K T}}\right)\right\rfloor,
$$

where $E_{F s}$ and $E_{F d}$ are the Fermi level energies at the source and drain, respectively. This equation for the current can be used in the linear and saturation regions.

\section{Gate and Carbon Nanotube Potential Relation}

Figure 2(a) shows the basic cross section of a CNT-FET including the charge distributions, Fig. 2(b) shows the corresponding potential distributions between the gate and substrate. In Fig. 2(a), charge distributions are explained as follows: the charge on the gate is $Q_{g}$, charges in oxide layers are $Q_{01}$ and $Q_{02}$, charge inside the CNT is $Q_{c n t}$ and the charge in the substrate

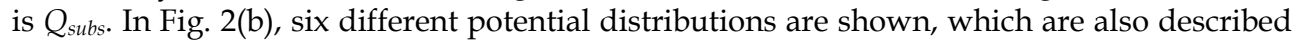
as follows. The voltage between the gate and the substrate (back gate) is $V_{g b}$, the potential drop across the oxides $\psi_{o x 1}$ and $\psi_{o x 2}$, the surface potential in the substrate with respect to the back gate is $\psi_{\text {subs, }}$, the potential across the CNT is $\psi_{c n t}$, and the work function difference between the gate and the substrate materials is $\phi_{m s}$. The work function, $\phi_{m s}$ can be divided in two parts and is expressed as follows,

$$
\phi_{m s}=\phi_{m c}+\phi_{c s}
$$

where $\phi_{m c}$ and $\phi_{c s}$ are the work function differences between the metal gate and carbon nanotube materials and the carbon nanotube and substrate materials, respectively. We can also combine potentials $\psi_{c n t}, \psi_{o x 2}, \phi_{c s}$, and $\psi_{s u b s}$ into a single potential, $\psi_{c n t, s}$, which describes the potential at the interface of the gate oxide and carbon nanotube with respect to the back gate, we can call $\psi_{c n t, s}$ the carbon nanotube surface potential.

Using Kirchoff's voltage law, the potential balance, and the charge neutrality condition, we can write for Fig. 2,

$$
\begin{gathered}
V_{g b}=\phi_{m s}+\psi_{o x 1}+\psi_{c n t, s}, \\
Q_{g}^{\prime}+Q_{01}^{\prime}+Q_{c n t}^{\prime}+Q_{02}^{\prime}+Q_{s u b s}^{\prime}=0 .
\end{gathered}
$$

The prime in Eq. (4) denotes the charge per unit area. From basic laws of electrostatics (Cheston, 1964; Langmuir, 1961; Shen \& Kong, 1995; Thomas, 1972), we can utilize Eqs. (4) and (5) and the charge modeling described in (Marulanda, 2009; Marulanda et al., 2008; Srivastava et al., 2009), to express the gate voltage in a CNT-FET as,

$$
V_{g b}=\psi_{c n t, s}-\frac{Q_{c n t}}{C_{o x 1}}+V_{f b}
$$

where $V_{f b}$ is the flat band voltage, which is the voltage needed at the gate with respect to the 
back gate to compensate for the band bending at the gate oxide and carbon nanotube interface and it is given by,

$$
V_{f b}=\phi_{m c}-\frac{Q_{01}}{C_{o x 1}}
$$

In addition, $C_{o x 1}$ and $C_{o x 2}$ are the oxide capacitances for the respective oxide regions, $T_{o x 1}$ and $T_{0 x 2}$ and are described for a carbon nanotube of length, $L$ and radius, $r$ as follows (Cheston, 1964; Thomas, 1972),

$$
C_{o x}=\frac{2 \pi \varepsilon_{o x} L}{\ln \left(\frac{T_{o x}+r+\sqrt{T_{o x}^{2}+2 T_{o x} r}}{r}\right)} .
$$

In Eqs. (6), (7), and (8), $Q_{c n t}, Q_{01}$ and $C_{o x 1}$ are the total charges and capacitance, respectively, which are obtained by multiplying $Q_{01}^{\prime}, Q_{c n t}^{\prime}$, and $C_{o x}^{\prime}$ with their respective areas.

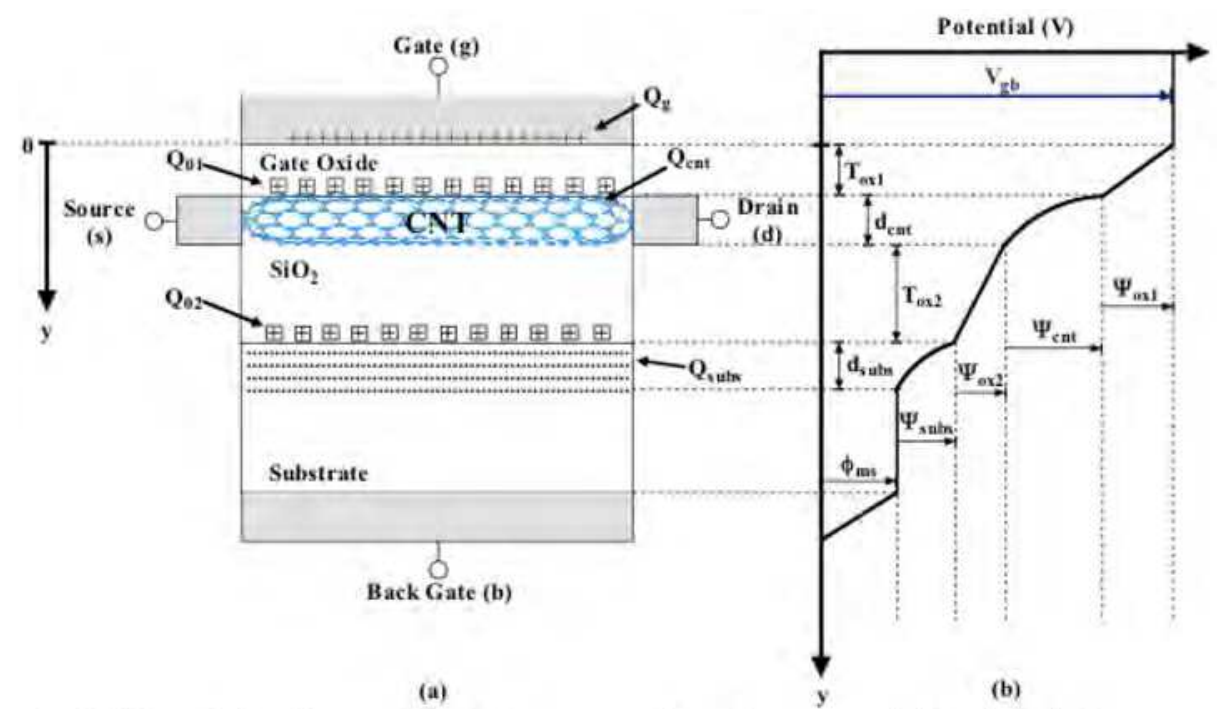

Fig. 2. (a) Plot of the charges from the gate to the substrate and (b) plot of the potential distribution from the gate to the substrate in a CNT-FET.

Using the carrier concentration modeling in (Marulanda \& Srivastava, 2008) and charge modeling described in (Marulanda, 2009; Marulanda et al., 2008; Srivastava et al., 2009), we can express Eq. (6) as:

$$
V_{g b}=\psi_{c n t, s}+\delta f\left(\psi_{c n t, s}, V_{c b}\right)+V_{f b},
$$

where 


$$
f\left(\psi_{c n t, s}, V_{c b}\right)= \begin{cases}I e^{\frac{\Delta E_{F}+q\left(\psi_{c n t s}-V_{c b}-\phi_{0}\right)-E_{c}}{k T} ;} ; & \text { for } \psi_{c n t, s} \leq V_{c b}+\phi_{0}-\frac{\Delta E_{F}}{q}+\frac{E_{c}}{q}-\frac{k T}{q} \\ \frac{\sqrt{\left(\Delta E_{F}+q \psi_{c n t, s}-q V_{c b}-q \phi_{0}\right)^{2}-E_{c}^{2}}}{k T} & \text { for } \psi_{c n t, s} \geq V_{c b}+\phi_{0}-\frac{\Delta E_{F}}{q}+\frac{E_{c}}{q}+\frac{k T}{q}\end{cases}
$$

and

$$
\delta=\frac{q L N_{c}}{C_{o x 1}}
$$

In Eq. (9), $V_{c b}$ is the induced potential between the carbon nanotube and the substrate due to the drain and source terminal voltages. The potential, $V_{c b}$ varies from $V_{s b}$ (source to back gate potential) to $V_{d b}$ (drain to back gate potential). Furthermore, in Eq. (10), $k$ is Boltzmann constant, $T$ is temperature, $\phi_{0}$ is the carbon nanotube surface potential, $q \psi_{c n t, s}$ when $V_{g b}=V_{f b}$ and $\psi_{c n t}=0, \Delta E_{F}$ is the shift in the Fermi level of the carbon nanotube depending upon doping, , $\phi_{0}$ and $\Delta E_{F}$ are given by,

$$
\begin{gathered}
\phi_{0}=\psi_{o x 2}+\psi_{s u b s}+\phi_{c s} \\
\Delta E_{F}= \pm k T \ln \left(1+\frac{N}{n_{c n t, i}}\right)
\end{gathered}
$$

where $n_{c n t, i}$ is the intrinsic concentration of a $\mathrm{CNT}(\mathrm{n}, \mathrm{m})$ and $N$ is the impurity doping concentration. $\Delta E_{F}$ is positive for an n-type carbon nanotube (donors impurity concentration, $N=N_{D}$ ) and negative for a p-type carbon nanotubes (acceptors impurity concentration, $N=N_{A}$ ).

In Eq. (10), $I$ is an indefinite integral involved in finding the carrier concentration of a carbon nanotube, we have found an analytical solution in (Marulanda, 2009; Marulanda \& Srivastava, 2008); however, the general form of the integral, I is given by,

$$
I=\frac{1}{\sqrt{k T}} \int_{0}^{\frac{6 E_{c}}{k^{T}}} \frac{\left(k T x+E_{c}\right)}{x^{1 / 2}\left(k T x+2 E_{c}\right)^{1 / 2}} e^{-x} d x
$$

The term $N_{c}$ introduced by Eq. (11) is found from our carrier concentration model for carbon nanotubes (Marulanda \& Srivastava, 2007; Marulanda \& Srivastava, 2008) and is given by,

$$
N_{c}=\frac{8 k T}{\pi V_{p p \pi} a \sqrt{3}}
$$

where $V_{p p \pi}$ is the carbon-carbon (C-C) tight binding overlap energy, $a$ is the lattice constant with a value of $\sqrt{3} a_{c-c}$, and $a_{c-c}$ is the nearest neighbor distance between C-C bonds $(0.144$ $\mathrm{nm}$ ) (Dresselhaus et al.). 


\section{I-V Characteristic Simulation}

Equation (9) cannot be solved explicitly for the carbon nanotube surface potential, $\psi_{c n t, s}$ in terms of the terminal voltages, hence, a numerical solution technique must be taken in order to find the exact channel potential given a gate voltage input.

In a CNT-FET, when the terminal voltages $V_{d b}, V_{s b}$, and $V_{g b}$ are applied, the two terms $\left(E_{F s}-E_{c}\right)$ and $\left(E_{F d}-E_{c}\right)$, referred in Eq. (2) can be replaced by $\Delta E_{F}+q\left(\psi_{c n t, s}-V_{s b}-\phi_{0}\right)-E_{c}$ and $\Delta E_{F}+q\left(\psi_{c n t, s}-V_{d b}-\phi_{0}\right)-E_{c}$, respectively (Marulanda, 2009; Raychowdhury et al., 2004; Srivastava et al., 2009; Tsividis, 1999). $V_{s b}$ and $V_{d b}$ are the source to bulk and drain to bulk voltages, respectively; furthermore, $\psi_{c n t, s}$ is calculated using Eq. (9) employing a numerical solution approach. Thus, our Eq. (2) becomes:

$$
I_{d s}=\frac{q k T}{\pi \mathrm{h}}\left\lfloor\ln \left(1+e^{\frac{\Delta E_{F}+q\left(\psi_{c n t s}(0)-V_{s b}-\phi_{0}\right)-E_{c}}{k T}}\right)-\ln \left(1+e^{\frac{\Delta E_{F}+q\left(\psi_{c n t s}(L)-V_{d b}-\phi_{0}\right)-E_{c}}{k T}}\right)\right\rfloor .
$$

The complete process to find the current $I_{d s}$ is as follows:

1. Define the voltages $V_{d b}, V_{s b}$, and $V_{g b}$.

2. Use a numerical method to find $\psi_{c n t, s}$ from Eq. (9).

3. Compute the current, $I_{d s}$, using Eq. (15).

4. Repeat steps 1 - 3 for each of the input voltages, $V_{d b}, V_{s b}$, and $V_{g b}$ combination.

Figure 4 shows the I-V characteristics for a CNT-FET with a carbon nanotube of chiral vector $(5,3)$ and diameter of $0.2759 \mathrm{~nm}$, under different overdrive gate voltages. These plots were derived following the four steps just mentioned.

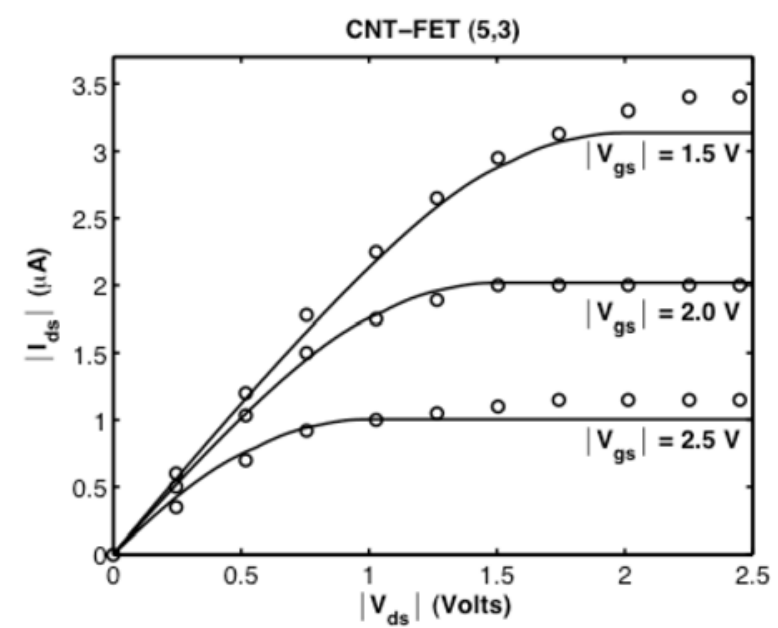

Fig. 3. I-V characteristics for a CNT-FET $(5,3)$ with $V_{f b}=0, \phi_{0}=0, \Delta E_{F}=0$, and device dimensions of $L=3 \mu \mathrm{m}, T_{o x 1}=500 \mathrm{~nm}$, and $T_{o x 2}=1 \mu \mathrm{m}$. 


\section{CNT-FET $(5,3)$}

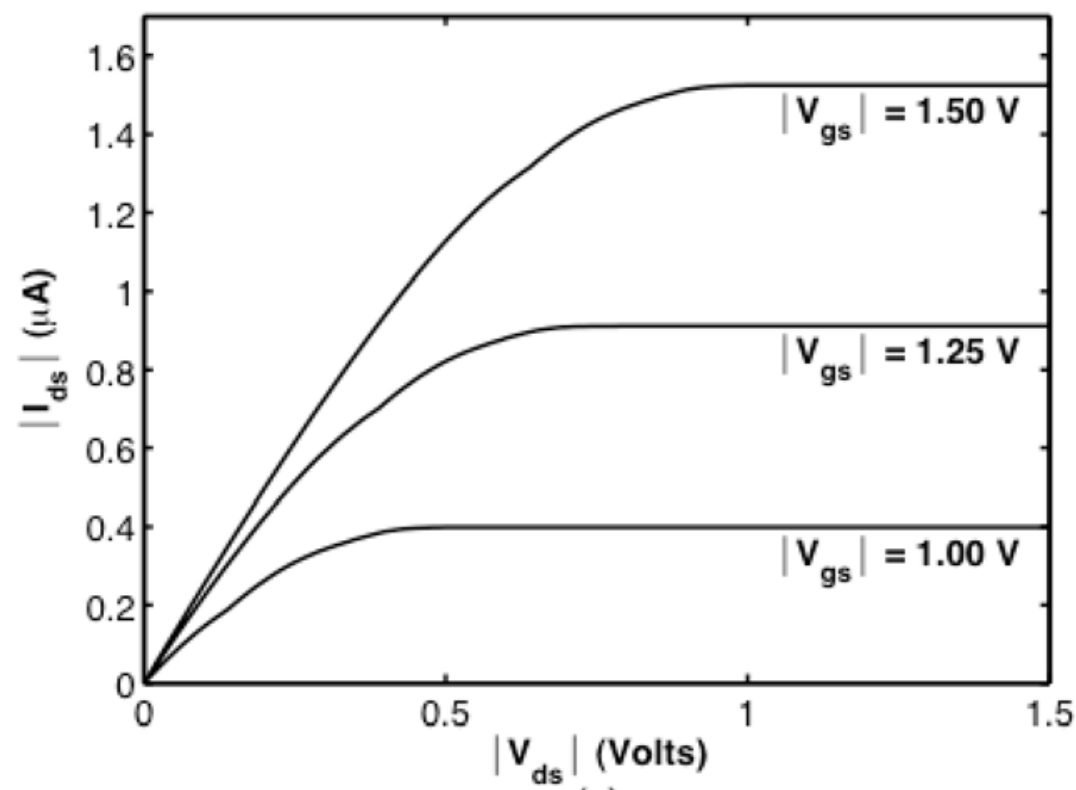

(a)

CNT-FET $(7,2)$

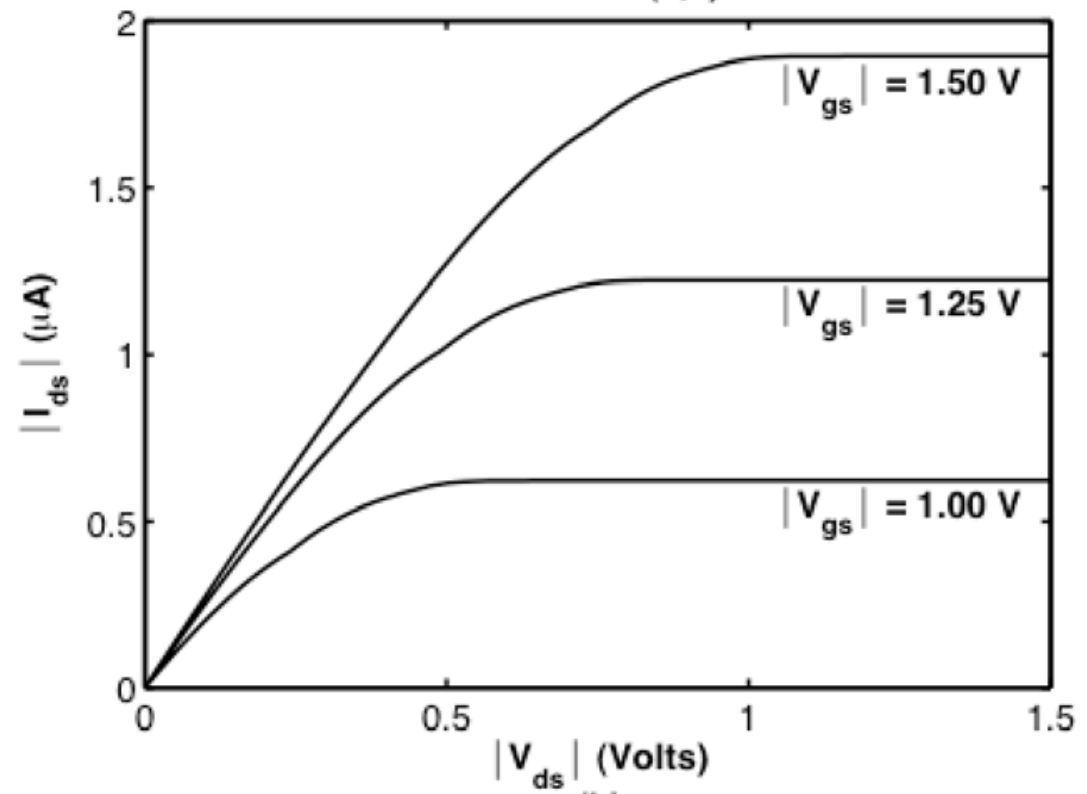

(b)

Fig. 4. I-V characteristics for (a) CNT-FET $(5,3)$ and (b) CNT-FET $(7,2)$ with $V_{f b}=0, \phi_{0}=0$, $\Delta E_{F}=0$, and device dimensions of $L=25 \mathrm{~nm}, T_{o x 1}=40 \mathrm{~nm}$, and $T_{o x 2}=400 \mathrm{~nm}$. 


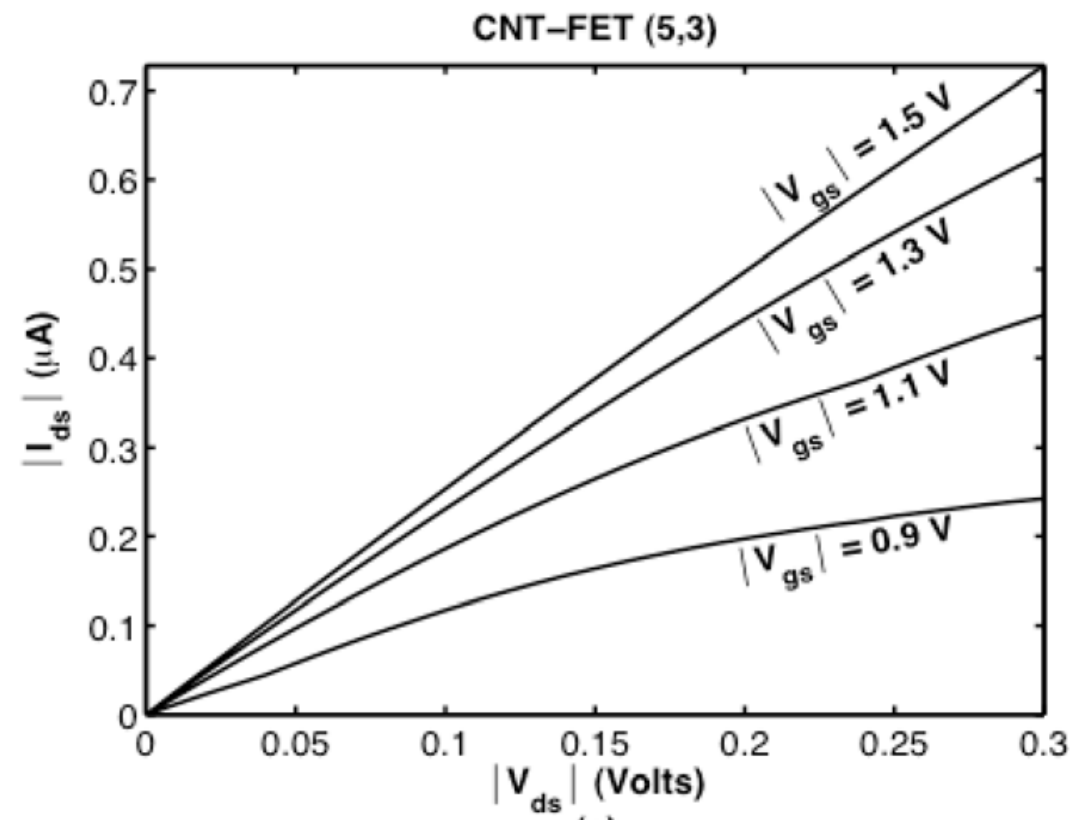

(a)

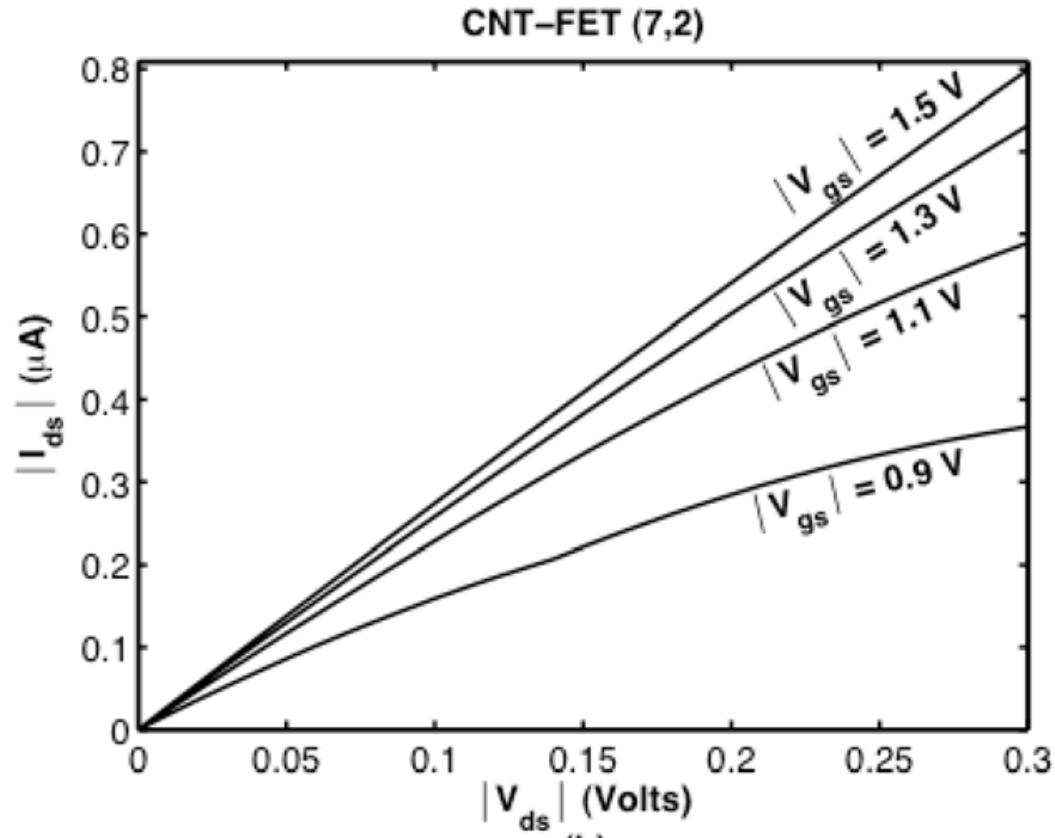

(b)

Fig. 5. I-V characteristics under low $V_{d s}$ for (a) CNT-FET $(5,3)$ and (b) CNT-FET $(7,2)$ with $V_{f b}=0, \phi_{0}=0, \Delta E_{F}=0$, and device dimensions of $L=25 \mathrm{~nm}, T_{o x 1}=40 \mathrm{~nm}$, and $T_{o x 2}=400 \mathrm{~nm}$. 
We have included in Fig. 3 experimentally measured data (Zhou et al., 2000) to validate the accuracy of our model. As we can see from Fig. 3, the model equation (Eq. 15) follows closely the experimentally measured data for the linear region. However, as the transistor enters the saturation region (in this region the current $I_{d s}$ begins to saturate and becomes almost independent of $V_{d s}$ ), experimental values deviate from the model equation since our model equation does not include a correction term for the saturation region similar to the channel length modulation parameter in a MOSFET (Antognetti \& Massobrio, 1988; Tsividis, 1999).

Using our numerical model approach we have also simulated the I-V characteristics for two more CNT-FETs. Figure 4 shows the I-V characteristics for two CNT-FETs with chiral vectors $(5,3)$ and $(7,2)$ and diameters $0.2759 \mathrm{~nm}$ and $0.3227 \mathrm{~nm}$, respectively.

Using the same procedure described for Figs. 3 and 4, it is also possible to compute the I-V characteristics for small $V_{d s}$. Figure 5 shows the simulated I-V characteristics for small $V_{d s}$ for the CNT-FET $(5,3)$ and CNT-FET $(7,2)$. As we can see in Fig. 5, for small $V_{d s}$ the current shows approximately a linearly proportional relationship to the voltage of the drain with respect to the source, $V_{d s}$.

\section{Conclusion}

Previous works in carbon nanotubes describing a relationship between the gate voltage and the carbon nanotube potential have made possible the implementation of a current equation, which can be solved numerically using any mathematical software, in order to find the current voltage characteristic for any given CNT-FET. The results presented provide designers with useful mathematical relations describing the properties of conductivity of carbon nanotubes and their response in circuit applications. Even though the charge transport in the carbon nanotube is not yet fully understood, and the solutions for the equations presented are strictly based in numerical methods, the results presented in this work set a starting point for device modeling simulation of carbon nanotube field effect transistors (CNT-FETs) and their applications on integrated circuits, including a SPICE compatible model.

\section{References}

Antognetti, P. \& Massobrio, G. (1988). Semiconductor Device Modeling with SPICE, McGrawHill, Singapore.

Baughman, R. H.; Zakhidov, A. A. \& Heer, W. A. d. (2002). Carbon nanotubes - the route toward applications. Science, Vol. 297, No. 5582, (August 2002), 787-792.

Chen, Z.; Appenzeller, J.; Lin, Y.-M.; Sippel-Oakley, J.; Rinzler, A. G.; Tang, J.; Wind, S. J.; Solomon, P. M. \& Avouris, P. (2006). An Integrated Logic Circuit Assembled on a Single Carbon Nanotube. Science, Vol. 311, No. 5768, (March 2006), 1735-1736.

Cheston, W. B. (1964). Elementary Theory of Electric and Magnetic Fields, John Wiley \& Sons Inc., New York.

Datta, S. (1999). Electronic Transport in Mesoscopic Systems, Cambridge University Press, New York.

Dresselhaus, M. S.; Dresselhaus, G. \& Avouris, P. (2001). Carbon Nanotube: Synthesis, Properties, Structure, and Applications, Springer Verlag, New York. 
Guo, J.; Lundstrom, M. \& Datta, S. (2002). Performance projections for ballistic carbon nanotube field-effect transistors. Applied Physics Letters, Vol. 80, No. 17, (April 2002), 3192-3194.

Iijima, S. (1991). Helical microtubules of graphitic carbon. Nature, Vol. 354, No. 6348, (November 1991), 56-58.

Javey, A.; Guo, J.; Farmer, D. B.; Wang, Q.; Wang, D.; Gordon, R. G.; Lundstrom, M. \& Dai, H. (2004). Carbon nanotube field-effect transistors with integrated ohmic contacts and high-k gate dielectrics. Nano Letters, Vol. 4, No. 3, (February 2004), 447-450.

Javey, A.; Wang, Q.; Ural, A.; Li, Y. \& Dai, H. (2002). Carbon nanotube transistors arrays for multistage complementary logic and ring oscillators. Nano Letters, Vol. 2, No. 9, (July 2002), 929-932.

Koo, K.-H.; Cho, H.; Kapur, P. \& Saraswat, K. C. (2007). Performance Comparisons Between Carbon Nanotubes, Optical, and $\mathrm{Cu}$ for Future High-Performance On-Chip Interconnect Applications. IEEE Transactions on Electron Devices, Vol. 54, No. 12, (December 2007), 3206-3215.

Langmuir, R. V. (1961). Electromagnetic Field and Waves, McGraw-Hill Book Company, New York.

Liang, X.; Wang, S.; Wei, X.; Ding, L.; Zhu, Y.; Zhang, Z.; Chen, Q.; Li, Y.; Zhang, J. \& Peng, L.-M. (2009). Towards Entire-Carbon-Nanotube Circuits: The Fabrication of SingleWalled-Carbon-Nanotube Field-Effect Transistors with Local Multiwalled-CarbonNanotube Interconnects. Advanced Materials, Vol. 21, No. 13, (April 2009), 13391343.

Lin, Y.-M.; Appenzeller, J.; Chen, Z.; Chen, Z.-G.; Cheng, H.-M. \& Avouris, P. (2005). HighPerformance Dual-Gate Carbon Nanotube FETs with 40-nm Gate Length. IEEE Transactions on Electron Devices, Vol. 26, No. 11, (November 2005), 823-825.

Martel, R.; Schmidt, T.; Shea, H. R.; Hertel, T. \& Avouris, P. (1998). Single and multi wall carbon nanotube field effect transistors. Applied Physics Letters, Vol. 73, No. 17, (October 1998), 2447-2449.

Marulanda, J. M. (2009). Current Transport Modeling of Carbon Nanotubes: Concepts, Analysis, and Design, VDM Verlag, Saarbrücken, Germany.

Marulanda, J. M. \& Srivastava, A. (2007). Carrier density and effective mass calculations for carbon nanotubes, Proccedings of the International Conference on Integrated Circuit Design E Technology (ICICDT), pp. 234-237, Austin, TX, May 30 - Jun 1.

Marulanda, J. M. \& Srivastava, A. (2008). Carrier density and effective mass calculations in carbon nanotubes. Physica Status Solidi (b), Vol. 245, No. 11, (November 2008), 25582562.

Marulanda, J. M.; Srivastava, A. \& Sharma, A. K. (2008). Threshold and saturation voltages modeling for carbon nanotube field effect transistors (CNT-FETs). NANO, Vol. 3, No. 3, (June 2008), 195-201.

Marulanda, J. M.; Srivastava, A. \& Yellampalli, S. (2008). Numerical Modeling of the I-V Characteristic of Carbon Nanotube Field Effect Transistors (CNT-FETs), Proccedings of the IEEE 40th Southeastern Symposium on System Theory (SSST 2008), pp. 235-238, New Orleans, LA, March 16-18.

Nihey, F.; Hongo, H.; Ochiai, Y.; Yudasaka, M. \& Iijima, S. (2003). Carbon-nanotube field effect transistors with very high intrinsic transconductance. Japanese Journal of Applied Physics, Vol. 42, No. 10B, (October 2003), L1288-L1291. 
Nougaret, L.; Happy, H.; Dambrine, G.; Derycke, V.; Bourgoin, J. P.; Green, A. A. \& Hersam, M. C. (2009). $80 \mathrm{GHz}$ field-effect transistors produced using high purity semiconducting single-walled carbon nanotubes. Applied Physics Letters, Vol. 94, No. 24, (June 2009), 243505-243503.

Shen, L. C. \& Kong, J. A. (1995). Applied Electromagnetism, PWS Foundations in Engineering Series, Boston.

Srivastava, A.; Marulanda, J. M.; Xu, Y. \& Sharma, A. K. (2009). Current transport modeling of carbon nanotube field effect transistors. Physica Status Solidi (a), Vol. 206, No. 7, (May 2009), 1569-1578.

Tanaka, K.; Yamabe, T. \& Fukui, K. (1999). The Science and Technology of Carbon Nanotubes, Elsevier, Amsterdam, The Netherlands.

Tans, S. J.; Vershueren, A. R. M. \& Dekker, C. (1998). Room-temperature transistor based on a single carbon nanotube. Nature, Vol. 393, (May 1998), 49-52.

Thomas, D. (1972). Engineering Electromagnetics, Pergamon Press Inc., New York.

Tsividis, Y. (1999). Operation and Modeling of the MOS transistor, McGraw-hill, Singapore.

Wallace, P. R. (1947). The band theory of graphite. Physical Review Letters, Vol. 71, (May 1947), 622-634.

Wang, D.; Wang, Q.; Javey, A.; Tu, R.; Dai, H.; Kim, H.; McIntyre, P. C.; Krishnamohan, T. \& Saraswat, K. C. (2003). Germanium nanowire field-effect transistors with $\mathrm{SiO}_{2}$ and high-kappa $\mathrm{HfO}_{2}$ gate dielectrics. Applied Physics Letters, Vol. 83, No. 12, 2003), 2432-2434.

Wei, B. Q.; Vajtai, R. \& Ajayan, P. M. (2001). Reliability and current carrying capacity of carbon nanotubes. Applied Physics Letters, Vol. 79, No. 8, (August 2001), 1172-1174.

White, C. T. \& Todorov, T. N. (1998). Carbon nanotubes as long ballistic conductors. Nature, Vol. 393, No. 6682, (May 1998), 240-242.

Wildoer, J.; Venema, L.; Rinzler, A.; Smalley, R. \& Dekker, C. (1998). Electronic structure of atomically resolved carbon nanotubes. Nature, Vol. 391, No. 6662, (January 1998), 59-62.

Wind, S. J.; Appenzeller, J.; Martel, R.; Derycke, V. \& Avouris, P. (2002). Fabrication and electrical characterization of top gate single-wall CNFETs. Journal of Vacuum Science and Technology B, Vol. 20, No. 6, (November 2002), 2798-2801.

Wind, S. J.; Appenzeller, J.; Martel, R.; Derycke, V. \& Avouris, P. (2002). Vertical scaling of carbon nanotube field-effect transistors using top gate electrodes. Applied Physics Letters, Vol. 80, No. 20, (May 2002), 3817-3819.

Wong, H. S. P. (2002). Field effect transistors - from silicon MOSFETs to carbon nanotube FETs, Proccedings of the $23^{\text {th }}$ International Conference on Microelectronics, (MIEL), pp. 103-107.

Xia, T.-S.; Register, L. F. \& Banerjee, S. K. (2004). Quantum transport in carbon nanotube transistors: complex band structure effects. Journal of Applied Physics, Vol. 95, No. 3, (February 2004), 1597-1599.

Xu, Y.; Srivastava, A. \& Marulanda, J. M. (2008). Emerging carbon nanotube electronic circuits, modeling and performance, Proccedings of the 51st IEEE International Midwest Symposium on Circuits and Systems (MWSCAS 2008), pp. 566 - 569, August 10-13.

Yao, Z.; Kane, C. L. \& Dekker, C. (2000). High-field electrical transport in single-wall carbon nanotubes. Physical Review Letters, Vol. 84, No. 13, (March 2000), 2941-2944. 
Zhang, Z.; Liang, X.; Wang, S.; Yao, K.; Hu, Y.; Zhu, Y.; Chen, Q.; Zhou, W.; Li, Y.; Yao, Y.; Zhang, J. \& Peng, L.-M. (2007). Doping-Free Fabrication of Carbon Nanotube Based Ballistic CMOS Devices and Circuits. Nano Letters, Vol. 7, No. 12, (November 2007), 3603-3607, 1530-6984.

Zhou, C.; Kong, J. \& Dai, H. (2000). Electrical measurements of individual semiconducting single walled carbon nanotubes of various diameters. Applied Physics Letters, Vol. 76, No. 12, (March 2000), 1597-1599. 


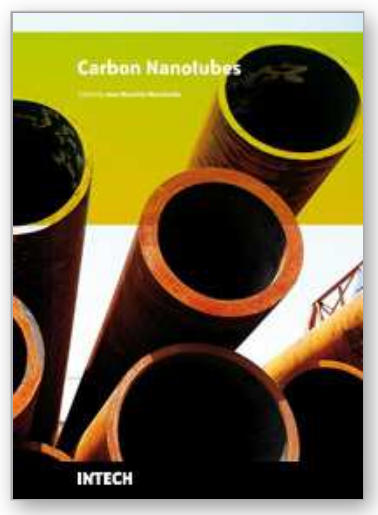

\author{
Carbon Nanotubes \\ Edited by Jose Mauricio Marulanda
}

ISBN 978-953-307-054-4

Hard cover, 766 pages

Publisher InTech

Published online 01, March, 2010

Published in print edition March, 2010

This book has been outlined as follows: A review on the literature and increasing research interests in the field of carbon nanotubes. Fabrication techniques followed by an analysis on the physical properties of carbon nanotubes. The device physics of implemented carbon nanotubes applications along with proposed models in an effort to describe their behavior in circuits and interconnects. And ultimately, the book pursues a significant amount of work in applications of carbon nanotubes in sensors, nanoparticles and nanostructures, and biotechnology. Readers of this book should have a strong background on physical electronics and semiconductor device physics. Philanthropists and readers with strong background in quantum transport physics and semiconductors materials could definitely benefit from the results presented in the chapters of this book. Especially, those with research interests in the areas of nanoparticles and nanotechnology.

\title{
How to reference
}

In order to correctly reference this scholarly work, feel free to copy and paste the following:

Jose Mauricio Marulanda and Ashok Srivastava (2010). Numerical Modeling of the I-V Characteristics of Carbon Nanotube Field Effect Transistors, Carbon Nanotubes, Jose Mauricio Marulanda (Ed.), ISBN: 978-953307-054-4, InTech, Available from: http://www.intechopen.com/books/carbon-nanotubes/numerical-modelingof-the-i-v-characteristics-of-carbon-nanotube-field-effect-transistors

\section{INTECH}

open science | open minds

\author{
InTech Europe \\ University Campus STeP Ri \\ Slavka Krautzeka 83/A \\ 51000 Rijeka, Croatia \\ Phone: +385 (51) 770447 \\ Fax: +385 (51) 686166 \\ www.intechopen.com
}

\author{
InTech China \\ Unit 405, Office Block, Hotel Equatorial Shanghai \\ No.65, Yan An Road (West), Shanghai, 200040, China \\ 中国上海市延安西路65号上海国际贵都大饭店办公楼405单元 \\ Phone: +86-21-62489820 \\ Fax: $+86-21-62489821$
}


(C) 2010 The Author(s). Licensee IntechOpen. This chapter is distributed under the terms of the Creative Commons Attribution-NonCommercialShareAlike-3.0 License, which permits use, distribution and reproduction for non-commercial purposes, provided the original is properly cited and derivative works building on this content are distributed under the same license. 